\title{
a $\begin{aligned} & \text { university } \\ & \text { of the arts } \\ & \text { london }\end{aligned}$
}

\begin{tabular}{|l|l|}
\hline Title & $\begin{array}{l}\text { Unbound: Beyond the Codex, The Book as } \\
\text { Process/Experience/Event }\end{array}$ \\
\hline Type & Article \\
\hline URL & https://ualresearchonline.arts.ac.uk/id/eprint/14166/ \\
\hline Date & 2017 \\
\hline Citation & $\begin{array}{l}\text { Calvert, Sheena M. (2017) Unbound: Beyond the Codex, } \\
\text { The Book as Process/Experience/Event. Book 2.0: From } \\
\text { Codex to Computer, 7 (1). ISSN 2042-8022 }\end{array}$ \\
\hline Creators & Calvert, Sheena M. \\
\hline
\end{tabular}

\section{Usage Guidelines}

Please refer to usage guidelines at

http://ualresearchonline.arts.ac.uk/policies.html or alternatively contact ualresearchonline@arts.ac.uk.

License: Creative Commons Attribution Non-commercial No Derivatives

Unless otherwise stated, copyright owned by the author 
Dr. Sheena Calvert: Camberwell College of Arts/Central St. Martins College of Art s.calvert@csm.arts.ac.uk

Themes: Books As Material Objects: the materiality of book creation, construction, production, use, reuse, and destruction. The Artists' Book: Binding/Process/Material.

\section{Unbound: Beyond the Codex, The Book as Process/Experience/Event}

"Between the too warm flesh of the literal event and the cold skin of the concept runs meaning... Every exit from the book is made from within the book" — Jacques

Derrida $^{1}$

"Our obsession with the book as the archetype of culture has not even encouraged us to consider the book itself as a peculiar and arty way of packaging experience" Marshall Mcluhan. ${ }^{2}$

\section{$\underline{\text { Introduction }}$}

Traditionally, the book has enjoyed a unique role and position as the authorizing vehicle by which language as logos and rationality is presented, with the codex being the principle artifact for the transportation of such knowledge, for over 2,000 years. Johanna Drucker eloquently describes the codex: 'The graphical configuration of the elements of a codex, for instance, is a highly structured code, a set of protocols that articulate and support meaningful relations among the parts of the book ${ }^{3}$. In contemporary explorations of the primary, intrinsic relationships between books and knowledge, and between books and human beings, much is made of the role of

\footnotetext{
1 Jacques. Derrida, Writing and Difference, (University of Chicago Press, 1978), p.75.

2 Marshall Mcluhan, (Counter-blast, 1969), p. 93.

39 Epistemological Essays, (Cuneiform Press, 2013), p. 121.
} 
'experience' in discussions of the physical book, and this implies a physicality attached to the ways in which knowledge is imparted, through haptic engagement with books as objects, and their status as enigmatically physical 'phenomena'. While McLuhan irreverently and offhandedly describes them as a "peculiar and arty way of packaging experience", he also points to a central concern of this paper: that the object 'book', ordinarily takes precedence over the experience of 'book'. The book as object is mythologized to the degree that in the present day, to cut the physical pages of an uncut, hand-bound book, is to perform an irreversible violence to the objecthood of the book, where once this was an ordinary (necessary) event. However, the process (event) of cutting the book reveals its contents; bringing its hidden knowledge[s] to light in the most 'performative' way, whilst at the same time emphasizing the 'objectness' of books, and their vulnerability/status, by posing them as something which can be violated.

In short, the book-as-object holds a particularly potent place in human intellectual and cultural life: one which takes the material object itself to be the locus of an intense questioning of the materialization of knowledge and of human experience. However, the emphasis on the physicality of the book in terms of knowledge, may be an illusion, since the counter argument is that books are only containers of metaphysical ideas, and as such, ideas can come to us in any form, even as dematerialized code. Does the book as a physical object which exists in time and space, and whose ontological and historical status is under attack, really constitute the space of a potentially more authentic engagement with knowledge and understanding than that of the digital book, or the e-reader? What, exactly, do we lose, and what is it that people regret the loss of, when moving from the physical book to screen? Is it the loss of sensual experience, 
Taking these questions as the departure point, this essay will talk about the book as process/material/ event; of the author's relationship to making, unmaking, and of the role of personal experience as an intrinsic part of the meaning of the book: one not bound to the book-as-object, and in fact emphasizing the process to such an extreme degree that it amounts to a fundamental disinterest in the final object: a dismissal of the book as a form of knowledge. I acknowledge the relative futility of such an endeavor, since to attempt to speak about process, post-event, is to risk falling into the paradox of representation. When all that remains is the trace of the process (the final work), and yet process is the subject of reflection, we are thrown into the abyss, where "thought [must] work against its own reification".

This paradox is where my own questioning of the book begins, with a query about the ways in which the object we call 'the book' can be disrupted, unbalanced and thought differently. I am particularly interested in the ways in which an intense engagement in the process of 'making', can lead to an understanding and presentation of 'the book' which are prescient within current debates about the book as material. Johanna Drucker, in '9 Epistemological Essays', states: “Material properties are not fixed essences, but capabilities, performative and potential, provocative and suggestive, alive and distinct in each instance of use", , suggesting that we might wish to rethink our relationship to the book as something which fixes thought, knowledge, and culture

${ }^{4}$ Sadler, G. B, 'Three Dialectical Relationships and the Necessity of Critique in Theodore Adorno's Works' 1999

${ }^{5}$ Drucker, J., '9 Epistemological Essays'. p.126 
in the form of an artifact. Questions of material/immaterial, or digital and analogue forms of 'the book' slip away in the face of a more fundamental questioning. I share Drucker's concerns about the relative poverty of the debates around the materiality of books, and the need to question materiality, fixity, and the illusion of the reification of thought in the form of the book.

\section{Book/Event}

"At yet another extreme, artists work against the progression of the book form. The inevitable one-thing-after-another aspect of the bound codex can create its own tensions. [A]rtists have reinforced the static potential of the book as a series of articulated but discrete spaces whose sequential relation is merely incidental. The unbound codex, card stacks and loose sheets in a box or portfolio, are the final dissolution of those forced linkages against which the conceptual unity of the book can be defined".

— Johanna Drucker, 'The Self-Conscious Codex', 1997

To begin then, from a simple observation: the book is a physical, sensual object, but it's also an 'event', in two senses of that term. One is the event of the object we encounter ${ }^{6}$, and the other is the event of its making. In my own work the physical act of making a book such as Skinful (Calvert, 2003/13), requires such an intensity of time and of making, that the book as a final object cannot be understood outside the second form of 'event' - the process by which it was made — including the conditions, experiences, physical restraints and the immersive emotional conditions under which the work was undertaken. The final work, is therefore bound to its making, and to the intimacy of time and production; in turn requiring a very different understanding of 'book'. The physical book as a container of knowledge occupies an iconic status, and

\footnotetext{
${ }^{6}$ I will later speak about the bookwork The Cruelty of the Classical Canon (Calvert: 2014) in this
} regard: as a site of material encounter. 
the relationship between books and their role in the transmission of knowledge. The dematerialized book can/cannot offer the same or a similar engagement with what it is 'to know' something. By emphasizing the book as process, rather than a physical object, the hope is to offer insight into the future of books, from the position of thinking through how content is constituted in the physical/immaterial book, and what potential implications this has for how we acquire knowledge and understanding in our culture at large. There is a larger question about the metaphysics of knowledge which cannot be detached from these observations, and to which I will return. However, to cite Adorno's edict about the problems of neatly 'packaged' conceptual thinking (italics my own):

"[t]he name of dialectics says no more, to begin with, than that objects do not go into their concepts without leaving a remainder, that they come to contradict the traditional norm of adequacy"'.

To consider a book in the fullness of its status as an experience/event, retains for thinking, the 'remainder' which Adorno points towards, and brings back the fullness of thinking which is embodied in the material act of making. Of course, I cannot be referring to the mass-produced paperback, whose material conditions of production are on such a scale, and so impersonal, that all traces of their making is erased. The examples I will discuss within this paper are from within the artists' books canon, and acknowledge all of their elitist positioning as art objects. However, when we talk of books, we primarily describe them, refer to them, and engage with them as objects, and explore these artifacts, detached from the time and process of their making. We think about books as temporally-bound objects, that is to say things which exist in

\footnotetext{
${ }^{7}$ Adorno, Negative Dialectics: $\mathrm{p} 5$
} 
time and space and which we experience in time and space, but not as enactments/embodiments of the time of their making and the time of experiencing their making: as 'events'. The observations I make here are offered not only from the point of view of the individual who encounters the text/book as a temporal 'object', as a user, reader, viewer, but also from the perspective of the maker who experiences books from within the event of their creation. These observations are especially pertinent to the hand-crafted book: the artists' book, since it requires a full immersion in the production process; one which is relatively unmediated, and highly personal. As a maker of books and especially as a maker of what we call 'artists books', time and the book are intimately entwined in my thinking: inseparable. One of my interests in this essay is therefore in reinstating an immanent understanding of not just the material object of the book (which we might pose as a final, concluded thought), but also to rethink the book as something bound to the time and process of its making, as an incomplete thought; whose final form consciously embraces the intensity of process: in which the making is the work, and which foregrounds this fact rather than erasing the traces of making in favour of the final object. In Gilles Deleuze's work, immanence is opposed to transcendence.

In Immanence: A Life, he writes: "It is only when immanence is no longer immanent to anything other than itself that we can speak of a plane of immanence." If immanence is immanent substance (immanent to itself), not immanent to substance, then by virtue of the same distinction, language, for example, is immanent in and of itself, not in relation to an outside (language is not a transcendental property, nor does it require an external reference to provide its meaning). In immanence, mind is not differentiated from body, in the Cartesian sense, and idealism does not involve the 
subject in a one-sided, unilateral mediation between itself, and external objects or events, where such mediation would normally seek to intervene between and resolve contradictions/ oppositions. Immanence does not involve oppositions. These questions and observations are both intensely personal and also intellectual. That is to say, they are intimate on a visceral level, from the perspective of a maker, and they also concern the ways in which knowledge is 'bound' to the materiality of language, the book, as a set of philosophical concerns.

The book as 'process' permits (insists upon) infinite readings and re-readings, always modified by the specificities of the moment we are in when we revisit it. In fact, this is the essential character of such a book. It promises nothing. It releases language (and the book) from its ancient promise to tell 'the truth', to codify, to render knowledge as if fixed in amber, set aside for future contemplation, and from its "conceptual unity", It requires a different experience and understanding of 'book'; one which acknowledges the impossibility of a singular reading which stands for all time, or of the stability of 'knowledge'. We know, instinctively, that the 'finitude' of the codex form is made a mockery of by the infinite dimensions of language, interpretation and time. ${ }^{9}$ Arguably, the book as an object is always at war with its contents (text/image etc), which refuse to surrender to its limitations. "The finitude of the codex is overwhelmingly a spatial rather than a temporal feature of its form”. Johanna Drucker points out that books continue to be read and reread over time, are read at the reader's own pace and in different orders, are reprinted. Books are the original nomads, crossing times, cultures, territories. "But there is an aspect of the codex's structure that emphasizes what might be termed its punctuality, or the making of definitive

\footnotetext{
${ }^{8}$ Op Cit. Drucker, 1997

${ }^{9}$ Op. Cit. Blanchot 1992, Jabez 1976-84
} 
spaces as moments within the continuum of the whole." ${ }^{10}$. This work I make explores books as finite/infinite experience[s] which further engage 'noisy' spatial/temporal/sensory attributes as part of knowledge. ${ }^{11}$ The philosopher Michel Serres thinks of noise as an unavoidable part of the transmission of information. Noise is a form of interference which happens in the process of moving any form of information between sender and receiver; one that occupies a frequency which registers chaos, disorder and nonsense as productive, not disruptive. Rather than seeking to eliminate noise as an unwanted 'excess' to communication, Serres suggests that it is precisely here, in the midst of this cacophonous environment, that there is the potential for new forms of thinking to emerge from the alternative patterns which are created. Noise, for Serres, implies movement and disruption, instability and disjunction, rather than linear, stable systems which cohere. Out of noise, new pathways, relations, movements, and assemblages are formed. Smell, touch, volume, texture, color, transparency, luminosity, endurance are all intrinsic parts of the work. Such books (arguably) retain an ability to embody knowledge as a material 'event': foregrounding their infinite interpretability over time, space, and shifts in meaning and context. If we can see "writing as an event and not as an entity", then we can see the book as an event and not as an object. As Drucker states: “ A book doesn't close on itself as a static, inert artifact between boards or covers ${ }^{, 13}$. It's an 'event' in the fullest sense of that term.

\section{Exiting Language/The Book}

\footnotetext{
${ }^{10}$ Op. Cit. Drucker, 1997

${ }^{11}$ Cf, Michel Serres The Parasite, (University of Minnesota Press, 2007) and Le Cinq Sens (The Five Senses), (Grasset, 1988).

${ }_{13}^{12}$ Drucker, 9 Epistemological Essays, p. 125

13 ibid. p. 97
} 
Jaques Derrida, Edmond Jabez, and Maurice Blanchot offer various critiques of the book $^{14}$ These writers employ a self-reflexive critique of language and the book, but one which contains a paradox. As Derrida points out in 'Writing and Difference': "every exit from the book is made within the book... everything that is exterior in relation to the book, everything that is negative as concerns the book, is produced within the book ${ }^{15}$. The exit from the book, the other and the threshold, are all articulated within the book'. Even the most radical excavators of language(including Lyotard/Derrida/ Nietzsche) have raised their questions from within the linear logic and 'law' of the book/text, often without directly addressing the form of the book as a static artifact which reifies thought. In contrast, Mallarmé's dialogue with the form of the text/book, offered staggeringly fresh philosophical insights into language and visual presentation where they entered into a more intimate relationship, and were treated as an 'event', something previously unthought.

A large part of my work over the last twenty years has been involved with such materializations of language, specifically through graphic design/typography and varied visual art practices. These representations of, and through, language are always paradoxical and witness/produce that paradox by being simultaneously concrete (material) and abstract (metaphysical/ephemeral). As an artist and design practitioner, I reached the point where I wanted to step back and rethink how language operated in my work, and this has led to an extensive engagement with various philosophies of language over the past few years. My work as an artist has persistently been concerned with looking closely at language, frequently taking the form of artists books and printed works which engage with unconventional literary forms (i.e.

${ }^{14}$ These include Edmond Jabez, 'The book of Questions' and Maurice Blanchot, 'The Absence of the Book' from within 'The Infinite Conversations'. (citations to come)

${ }^{15}$ J. Derrida, 'Structure, Sign, Play', in Writing and Difference, (Routledge, 1978), p.360.(check) 
creating a visual/sculptural 'skeleton key' to James Joyces' Finnegan's Wake, 1990, fig 1). Attempts to materialize, provoke, and stimulate an engagement with languages' excessive, affective, non-representational qualities: those aspects which cannot be accounted for within conventional theories of representation, or philosophies' of language have been at the core of my concerns. This work stemmed from an observation: when reading critiques of language from within linguistics or philosophy, something was missing: the experience of language as a material 'event'. It proposed that the fullest power of language to represent ideas about language resides in material form(s); in the experience of language and that this 'opaque surface of language'; sensory, tactile, spatial, acoustic, combines to invent what I would term a 'poetics of material language' which moves beyond concepts and invests in sound, form, rhythm and image as meaning.

The medium I chose to work with for this series of works, the artist's book, was employed in order to explore in depth the affective and sensory properties that lie within language as a material structure, in close conjunction with the more abstract argument. In them, I attempted to exploit to the full, the potential of joint studio/theoretical research. By crafting these volumes by hand in most cases, and pushing the physical limits of the processes I chose (such as silk-screen/binding/ letterpress printing), I wanted to create works which were rich physical experiences of language, not second-hand explanations. My larger aim was/is to bring about a 'fullblooded' encounter between intellectual and creative reflections on the subject of language and in turn 'the book'. A selection of past works includes 'Silence' (fig. 2/2a), a book containing a single word, each page obscured by a pristine sheet of black, sink-screened ink. The austerity and emptiness of this visual remark is 
unsettling, especially in the context of a hand-tooled, leather-bound volume, which would seem to promise so much more content. The book is hand silk-screened, with two 'runs' required. The first involved printing the word 'silence', and the second, obscuring it with a single sheet of black ink. All that remains visible is the slightest hint of the word, as a result of two thicknesses of ink, visible only in the correct light. I will now describe the experience of making two bookworks, separated by 10 years and by conceptual and material differences but whose meaning is each inextricably linked to the process of making, and both of which address questions of subjectivity and objectivity as well as the 'event'. One is the book entitled Skinful, and the other is The Cruelty. The first is a piece which is bound to the experience[s] of time and endurance, and the second is tied to weight and physical extremes, which deny the function of a book. The work is ongoing, and driven by an immersive process and ongoing dialogue with process and form.

\section{$\underline{\text { Skinful }}$}

Skinful (2004) is a unique group of 542 letterpress-printed, large-format unbound sheets. Constrained within the severe limits of physical production means; attentive to the minutiae of material/surface anomalies; it multiplies a single moment of making/reading to almost unendurable limits, where a single pass of ink is slowly drained away over the course of time, as the printing proceeds, proposing that the performance of making language, or of 'making sense', is equally important, if not more so, than its referential function.

Paradoxically, and in a way which complicates any 'reading' of it, Skinful (2003/2013) exists both as a set of unbound sheets as well as a bound book. In its first 
iteration, the printed sheets are gathered into the more conventional form of a 'book'. In the second, ignoring the need for the forced linkages provided by the tradition of the Codex, the book simply consists of the same word, printed repetitively, in the same position on sheets of paper. Printed letterpress, and (by necessity) in a single session, whose length is determined by the time taken to drain the ink from the press, the only thing that changes is the amount of ink with each 'pass' reducing almost imperceptibly over time and creating modulations of color and texture as the inherent qualities of wood on paper become apparent as the ink lessens (including wood grain, visible evidence of old 'wounds' to the letters becoming more or less visible at different points, ink coverage variance caused by the rollers which apply the ink, dust which adheres to the type). As a single inking slowly but continually 'drains' from the letters, each page reinforces different aspects of language, space, the form of letters, and process, while foregrounding 'time'. Due to the fact that the ink is slowly but continually 'draining' from the letters, each print is unique, revealing different aspects of the letters and of the process. It forces the reader (and the artist) to focus on the single word Skinful, its meaning, its banality, its excessive, domineering presence on the bare white. And then, at some point, the skins of the letters themselves become apparent, the edges of the letters dominate and the void of the interior is revealed (its presence/absence).

This book is not meant to be read in a linear sequence, but experienced as an endurance, an 'event', a series of slices of one moment of act of reading, extended to the extreme. And in the extension, there is the potential for a different kind of comprehension, a longer, drawn-out reflection of the meaning of the word itself, intimately related to the process of production and the economy of means employed 
in its production. There is finitude (the finitude of the ink which makes a 'presence' on the paper, but even when it is exhausted, the impression of the letters on the paper remains and could, theoretically, continue infinitely (paper and 'life' permitting). In a sense, this book is only one moment, one thought, expended to a painful level of endurance for both producer and reader. The rigor, effort, and mastery involved in the extended (singular, since it must all be done, by necessity at the same time) printing process speaks to the conceptual purpose of the book. Process and form are as one. Does binding the book constrain it to a physical and conceptual dimension that limits its operations? (meaning to that of 'Codex'?.). In contrast, each unbound page is a 'moment'; a fragment of a floating multiplicity. Each page is a statement. A 'moment', a slice of such a multiplicity). Everything I thought about as I made the book is inscribed here on an invisible, unstated, 'absent/present' dimension of the process and by implication is inscribed invisibly on the object produced. Saying something without saying it. Acting as silent witness: silence in the statement. Deep, boundless anger and pain, exquisitely constrained within the 'bounds' of the page, pushed hard up against the limits of the process, capable (in danger) of breaking free at any moment. I wanted to scream and cry but instead I contained all that emotion within the limits of the page which provided both constraints and liberation. The book is a mnemonic device for recalling the emotions I experienced at that moment. And yet, it never can recall them in the same exact way. Skinful was/is an 'event', not a book.

The book as process permits (in fact insists upon) infinite readings and re-readings of the same moment, always modified by the specificites of the moment we are in when we revisit it. In fact, this is the essential character of such a book. It promises nothing. It releases language (and the book) from its ancient promise to tell 'the truth', to 
codify, to render experience as if fixed in amber, set aside for future contemplation. It requires a different experience of 'book', one which acknowledges the impossibility of one reading which stands for all time. It privileges hermeneutics and sees that as an asset, not a detriment. We know that the 'finitude' of the codex form is made a mockery of by the infinite dimensions of language, interpretation and time. The book is always at war with its contents (text/image etc), which refuse to surrender to its limitations. Books continue to be read and reread over time, are read at the reader's own pace and in different orders, are reprinted. Books are the original nomads, crossing times, cultures, territories: spatial/temporal/sensory (smell, touch, volume, texture, color, transparency, luminosity. The invitation to turn the pages of such a book, becomes an endurance in and of itself: one which mirrors the 'weight' of its process of making. I can never revisit these emotions, or the sheer physical labour involved, and the second version of the work, with over 10 years' distance, is only a replica of the original 'event'. To reiterate: the artists' book is a physical sensual object, but it's also an event of making. Why do I reinforce this? Because in my work the physical act of making a book such as Skinful requires such an intensity of time and an intensity of making that the book as a final object cannot be understood outside this process. The work is bound to its making and to the intimacy of time and production. This requires a very different understanding of 'book'.

\section{The Cruelty}

This most recent artwork: The Cruelty of the Classical Canon (2013/14), is also in the form of an artists' book. ${ }^{16}$ The work is one part of a larger body of research,

\footnotetext{
${ }^{16}$ The Cruelty of The Classical Canon a process bookwork by sheena Calvert, 2014... This work was produced specifically for the exhibition: The Book: Materiality and Making', with Christine McCauley, emma Dodson and Katherina Manolessou (Gallery West, u. of Westminster, from February $4^{\text {th }}$ to March 7th 2014).
} 
entitled materialanguage, which touches upon contemporary concerns about retaining the sensual, human attributes of language and in turn 'the book' in an age of digital transformations and dematerialized, screen-based outputs, claiming that such works retain a place for both the process of making-and of experience-as a form of critical thinking; about language, culture, technology, and the question of the 'human'.

The Cruelty expands and touches upon some of the same paradoxes of the material book as a container of knowledge, but explored through different material means. A metal binding is the first 'sign' of the dialectic between form/content, and the books' relationship to the question of the body/embodied thought. ${ }^{17}$ The intention of The Cruelty of the Classical Canon is to critique the weight of the classical canon of texts which dominate the intellectual, cultural and literary landscape of Western thought ${ }^{18}$. The Cruelty metaphorically stands for the stasis of written language, ideas, intellect, culture: expressed by the rigidity of iron, steel, and paper, which offer limits, boundaries and physical restraint [the law]. As Persig states, Phaedrus:

"[C]ame to hate them vehemently, and to assail them with every kind of invective he could think of, not because they were irrelevant but for exactly the opposite reason. The more he studied, the more convinced he became that no one had yet told the damage to this world that had resulted from our unconscious acceptance of their thought."

Here, Phaedrus is referring to the classical texts of the Western tradition in the University of Chicago's 'Great Books Program'. The process by which the book was

${ }^{17}$ Op Cit., Serres, 2008

${ }^{18}$ Robert M. Pirsig: Zen and the Art of Motorcycle Maintenance. (Bantam, 1975).. 
made responds to this notion of damage and cultural and intellectual weight, by involving an intensity of making which dominates the final object and places the drama of physical presence and material force at the forefront of any experience of the work. Weighing over 30 kilograms; encased in a hand-forged iron cover made from 130 year old steel and iron, and with over 2,200 pages of blank text, the book block involves an exposed sewn binding which itself tests the limits of that process. It asks us to rethink the book as an iconic cultural arte[fact] which shapes our encounter with ideas, by focusing our attention on both the process of making and the book-asobject; one which does not offer any conclusions or overt commentary. The comingto-prominence of iron blacksmithing within ancient societies, and the invention of the alphabet are historically linked: 3,200 years of culture in the West are made possible by the prevalence of both iron and alphabetic writing.

The Cruelty does not attempt to illustrate its concept, nor does it state its claims overtly, but asks us to empathise with its premise, through the sheer force of material 'encounter' as metaphor. It seeks to compel, not to communicate, to engage, not to explain, to offer material disruption in place of description. The title The Cruelty of the Classical Canon is a way of naming the divisive and problematic historical separation of ideas from their embeddedness within a material or bodily 'event'. Language first cuts us away from experience, and the book completes this process of alienation. Finally, we are asked to accept predetermination in thought, as truth. We become weighed down by these assumptions, unable to move freely (figs 4-9).

The ability to empathise involves recognizing an 'other': it creates a bond between oneself and the 'out there': a mutual exchange. An object which embodies empathy 
similarly draws the 'other' to it, creating a connection and a space of deep reflection on complex matters which lie beyond its immediate physical manifestation. It does more than represent, it 'presents', and in that presentation, it calls attention to the power of 'encounter', and its correlate, emotional resonance. The Cruelty metaphorically stands for the stasis of written language, ideas, intellect, culture: expressed by the rigidity of iron, steel, and paper, which offer limits, boundaries and physical restraint [the law].

An empathetic object reaches beyond itself, to form a connection with that which lies beyond its boundaries. It reaches out, to extend its concept, and in doing so the empathy is returned. A 30kilogram book, hand-forged from 130 year old steel and iron, whose 2,200+ pages are yet blank, is a fully 'present' object, and yet one which has no purpose: it cannot be ignored, it just 'is' (this book is empty, it cannot be fully opened, it is mute). It offers a distillation of its concepts. We are drawn towards the material enigma of such an object precisely because it poses a contradiction: its drama is part of its meaning. It speaks silently, and in layers of material meaning which must be supplied by the viewer.

The Cruelty is a fully 'present' object, and yet one which has no purpose. The book is empty, and cannot be fully opened, and yet we are drawn towards the material enigma of such an object precisely because it poses a contradiction. This is where material empathy or empathetic materiality create 'affect': in the oscillation between the object and the viewer, such that a true dialogue takes place. The still, but forceful presence of material becomes a powerful response/rebuttal to the stripped-down, bloodless encounter of abstraction. The metaphysics of ideas is replaced by the sheer brute force 
of the physical act of making alongside the-book-as-thing, placing material empathy at the very core of meaning ${ }^{19}$.

Lyotard's Discourse/Figure, offers a further point of departure for this work, but by analogy. As Lyotard explains, by convention, both language and images are supposed to 'point', away from themselves, and towards another concept, reality, or object; becoming the primary interface between us and the 'out there'. However, by referring only to themselves, such matters become complicated, since when the 'surfaces' of the work itself are emphasised, and not their representational function, the usual distinctions between what Lyotard has termed discourse and figure (Lyotard 2011), text and image, sign and the reality it seeks to describe, collapse in a vortex of selfreferentiality, becoming semiotically stripped bare. When images and text take themselves as subject-matter, we are entered into a paradoxical space, where initially, it is not clear what signs are under these conditions. They initially seem to have no role, and, upset notions of transparency and instrumentality in communication, by pointing towards themselves, and nothing else. They come to possess a full opacity, or material thickness constituting what Lyotard has also called a 'scandalous' form of materiality, which disrupts the conformity of textual relations (Lyotard 2011). I would argue that this same argument could be applied to a book with no function, and one whose process of making takes precedence over the final artifact. Christian Cappuro's 'Another Misspent Portrait of Etienne de Silhouette' (figs. 10/11) is also a form of book-as-process; one which . As an object it consists only of pages of erased imagery. The flashes and detours which form the meaning of the work, are buried in the process, but glimpsed sideways to the main structure of the piece. They are 'para'

\footnotetext{
${ }^{19}$ A version of this text was first published in Varoom, 2013. (citation to be provided)
} 
to any communicative intent. The function of 'magazine' is rendered secondary to this process of erasure. Only the traces of this process remain, as markers of the event of its making.

\section{The Book-as-Process/Subject and Object}

Objectivity is usually posed as more reliable than subjectivity; more concrete, and yet the relationship between the two is much more subtle. Adorno reminds us that within the objective, the subjective always lingers; embedded and reciprocal. For example, to reflect upon our identity is to treat ourselves as an object of study, and where the objective might be presumed there is always a subject (ourselves), mediating our experience of it. "No matter how deeply we retreat into the subject, there is an object" (and vice versa). It's as though we are always 'dancing' with the other term, whenever we try and separate them out, for the sake of clarity. Adorno simply states that: "The distinction between subject and object is both real and illusory". 20

He reminds us that objects do not have an existence independent of our subjectivity, and this experience is further tied to history. We are historically constituted beings, and the dynamic of historical progress (of which we are a part), always impacts upon what counts as knowledge at any given time.

At the same time that we are subjects we are objects in the world as well.

Grammatically speaking, if one were to say "I take a drink", the "I" is the subject. To replace the "I" with a "Me", the "I" becomes an object. To this extent, subject and

${ }^{20}$ Op Cit., Adorno, 498 
object are completely intertwined with each other. Subjectivity is not a subject, it is an object as well and the subject is then of and a part of the world at large. ${ }^{21}$

Beatrice Warde argues that text should be invisible to content, but it's never invisible, it's never without a certain degree of presence, and is always modified by the relationship between subject (ourselves) and object (content), between word and thing, text and self, and by extension, book (object) and experience (process). The very invisibility that Warde argues for implies a metaphysics of language that can never exist: materiality, or the 'window' is always there, just to differing degrees of 'visibility'. Artists, typographers, illustrators, writers, who play with the visibility of text and books, are simply foregrounding it, making it 'conspicuously visible', and in the works I have presented here there is a conscious desire to draw attention, not only to the materiality of text/book, but to complicate matters by foregrounding process and event, and an embracing of subjective experience.

Text-as-image is a process, a method, a means of interrogating language from within; immanently, not by adding another discourse on top, in yet another meta-language or system which tries to explain it as a phenomena. You cannot get a 'view from nowhere' when writing about language, because you have to use language to do so; your object of scrutiny is also your means of expression. Similarly, in such work as I have highlighted here, the book itself is the process and object of reflection, with all of the paradoxes implied. By recognizing that there is no 'view from nowhere', which would erase any traces of subjectivity, perhaps I wish to suggest that such work

21 Adorno, Subject and Object. Accessed at: http://frankfurtschool.wordpress.com/2008/02/12/classsummary-subject-and-object-by-theodor-adorno/ 
performs a more authentic engagement with its subject matter. Artists, typographers, designers and book artists are concerned with 'making' language/the book, and so their meditations are coherent with experience of such media, not simply performing an analysis of these forms. They enact the power of letting language and the book speak for themselves, through process, experience, and event.

While Lyotard uses the example of text in his writing, as way to suggest an augmentation to the logic of representation, by a focus on the material, or medium, this point can be made with respect to the plasticity of the book, which, it can be argued, are internally differentiated when they self-refer, and accentuate process over outcome, in turn breaking with the denotative function of books. This discursive, figural and event-based narrative of the book can be seen in examples of self-referring work, which creates a new logic of representation, one which is not limited by the fixity of the material object of the book, but which plays in the paradoxical spaces of the non-representational, immaterial attributes of the book-as-process and event.

These are the kinds of events which precede/exceed the representation. This is what I am arguing is the 'book-as-process'.

Typographers, writers, designers, artists and book makers whose work considers, uses, questions, and re-figures the discourses of language and books have always been concerned with redefining philosophies of language, the book, and aesthetics, whether consciously/explicitly, or not. By stepping outside the dominant textual discourses, such work enacts, performs, and mines the richness of the material event of making; inflecting, and complementing those discourses on the languages of form, and 
meaning, with a new energy drawn from the consideration of materia prima ${ }^{22}$ and the temporal event of making. In related research, I have applied this thinking to language, outside the context of the book proposing to call this kind of self-referring, figural/plastic language: Materia Prima, referring to the Latin term for 'primary matter', or 'first source'. It was used in this context to suggest that language which has no function other than to be an image of itself, or to refer to its own 'surfaces', possesses an almost alchemical quality, comprised of formless, undifferentiated base material[s], which nonetheless possess enormous creative and analytic potential.

Martin Jay provides a helpful analogy, that of understanding such work in terms of a 'force-field', or a "relational interplay of attractions and aversions that constitute a dynamic structure". This sort of structure dispenses with the need for an 'either/or', the establishment of truth or untruth, within critique, such that a perpetual, oscillating paradox is generated by the movement of multiple terms, within fleeting, temporary assemblages (constellations). Avoiding foundations, origins, ground, or 'grand ideas', in the search for a 'groundless critique' occupies an extreme position in the debates between modernity, postmodernity, and beyond, and offers insight into philosophical, literary and artistic projects alike.

\section{Conclusion}

But, we might argue, aren't these experiments with the book-as-process too abstract? I would say no, since they remind us that books are always already abstract, and that we need to be on guard against confusing them with direct, unmediated communication. The book is just another 'language' we speak, a set of ideas, or as

\footnotetext{
${ }^{22}$ Cf Materia Prima (reference)
} 
Drucker remarks: "the book is not a unity, it's a conceptual unity, alone"23. Any form of language mediates: it forms a bridge and a barrier between ourselves and the world, as do books. In doing so, they shape our understanding and experience of that world. Books contain experiences, not just 'facts', and so the book-as-process reveals the contingent and experientially bound nature of these mediations. This work starts from a series of basis questions. Does the very act of stabilizing an idea, on the printed page, (in words) bestow upon it a kind of irreducible certainty; an ordained status, achievable through the fixity of forms such as language. book? This would presume that the very act of authoring something is a bestowal of truth, in and of itself, and that it 'objectifies' general, verbal, or unstable ideas into concrete pieces of knowledge/facts/wisdom, in turn raising issues of who has access to those vehicles of expression, through the medium of the language/the book.

Artists, typographers, illustrators, bookmakers and many writers, intuitively understand this, and demonstrate that understanding in their diverse, replete, and multi-sensual works. Their commitment to the exploration of the interface between the textual and the visual, the linguistic and the imagistic, the sensual and the conceptual brings a richness to our experience of language and the book, which is 'proper', as well provocative, and deeply philosophical. The process is the other content, since in Skinful, or Christian Cappurro's work, the process is the message of the work: the endurance is the event, and the final object we call a book, only the outcome of that process. There is no way to replicate the experience; the inhabitation.

\footnotetext{
${ }^{23}$ Johanna Drucker, 9 Epistemological Essays p. 96
} 
Finally, perhaps philosophy reaches its limit, but also its potential, where the only way to explain a philosophical idea, is not to illustrate it (in the sense of something secondary to the text: accompanying it), nor to describe it, but to inhabit it, to take up a space within it, fully, experientially, and without prejudice; frequently every bit as much through process, not just at the level of formal outcomes.

Philosophy is not theory; it is an art of plunging into this peculiar zone of "the unthought', that destabilizes clichés and ready-made ideas, in which both art and thought come alive and discover their resonances with one another- John Rajchman 24

Such interrogations of the primary conditions of language/book, through a focus on process not object, implicitly close the space between object and event (subject and object), as they purposefully play within that traditionally unexplored space and focus on experience. ${ }^{25}$ They exploit the space rendered irrelevant by others; sketching new and vibrant lines of inquiry. As I have stated in previous writings ${ }^{26}$, this is the knowledge that writers, artists, designers, typographers and illustrators bring. A respectful revision of John Dewy's words makes clear what is at stake: “All language, [and all books] whatever [their] medium, involve what is [said or made], and how it is [said or made], or substance and form". Maurice Blanchot eloquently states the dynamic under which research operates:

"All research is crisis. What is sought is nothing other than the turn of seeking, of

\footnotetext{
${ }^{24}$ J. Rajchman, The Deleuze Connections. (Massachusetts: The MIT Press, 2000). p.115

${ }^{25}$ John Dewey, Art as Experience p.106.

26 Cf Materia Prima (Intellect)
} 
research, that occasions this crisis: the critical turn."27 — Maurice Blanchot

Blanchot reminds us that in order to undertake authentic research, you don't set out on a journey to prove what you already think; you don't take as a given what you set out to prove. Research is a process, and should be treated as such. It's not oriented towards any particular object or outcome (this would weight it towards that outcome, and hinder its potential), but towards revealing hitherto unknown aspects of a subject, with a view towards 'revelation'. However, research also involves the risk of getting lost, of failing, and of being increasingly (not less) confused, through a process of wandering, along with the uncomfortable experience of being 'blind' at the outset, and at many points along the way. Meanwhile, as we follow our instincts, pursuing a subject from various angles; tracing the multiple trajectories and avenues which come into view along the way, it becomes clear that the purpose of research is to go on a journey, with no certainty of success, and to be confused most of the time: to be immersed in process and to lose track of time. To treat the book as process is to emphasize the temporal, experiential and highly contingent nature of 'knowing' itself.

\section{References}

Jabez, E. The Book of Questions, Wesleyan, 1976-84

${ }^{27}$ M. Blanchot, The Infinite Conversation (University of Minnesota Press, 1992). 
Blanchot, M. The Infinite Conversation (Theory and History of Literature), University of Minnesota Press, 1992.

Drucker, J. The Century of Artists Books, Granary, 2004.

Drucker, J. The Self-Conscious Codex: Artists' Books and Electronic Media

Source: SubStance, Vol. 26, No. 1, Issue 82: Special Issue: Metamorphoses of the

Book, (1997), pp. 93-112.

Serres, M, The Five Senses: A Philosophy of Mingled Bodies, Continuum, 2008.

Derrida, J., 'Edmond Jabès and the Question of the Book', essay, published in Writing and Difference, Routledge, 2002

J. Rajchman, The Deleuze Connections. (Massachusetts: The MIT Press, 2000).

Materai Prima

Varoom article 